\title{
Analysis of the Asynchronous Motor Controlled by Frequency Inverter Applied to Fatigue Test System
}

\author{
Nel Yuri Huaita Ccallo, Omar Chamorro-Atalaya \\ Faculty of Engineering and Management \\ National Technological University of Lima Sur \\ Lima, Peru
}

\begin{abstract}
This research focuses on analyzing the functional and operational parameters of the three-phase induction motor, squirrel cage type; Where the experimental model consists of a fatigue test system operated by two types of control: Control by Frequency Inverter and Classic star-delta control, where the engine load consists of a standard specimen, corresponding to $61.9 \%$ of the nominal load of the object of study. Experimental evaluations of this rotary machine are at regular operating conditions. Managing to Record electrical, mechanical, thermal variables; in a database where they were classified, developed, analyzed and interpreted; Highlighting from the graphs, the quasi-constant behavior of the $\operatorname{Cos}(\varphi)$ at 0.754 at different regulated frequency values which lead to a low energy consumption of current 1.88 Ampere with variator with respect to the weighted of 2.04 Ampere without inverter; even with improvements in torque when you are opting to use the drive from a $0.71 \mathrm{~N}-\mathrm{m}$ to a $0.94 \mathrm{~N}-\mathrm{m}$. Likewise, the operation of this machine at low frequencies manifests some damages to normal operation, such as the rate of increase in the operating temperature of $78.76{ }^{\circ} \mathrm{C}$ in a short time and with projection to increase. Similarly, the injection of harmonic distortion into the network as a result of using electronic equipment, contributes to the detriment of energy quality.
\end{abstract}

Keywords-Induction; torque; frequency inverter (VDF); current; harmonic; temperature

\section{INTRODUCTION}

The constitution of an asynchronous electric motor based on the squirrel cage model, presents the condition of gradual variation of speed by controlling the frequency of the stator, and the particularity of modifying the pole numbers in the inductor winding with the automatic adaptation of the same pair of poles in the rotor [1].

According to the constructive differences of electric motors, the types of lower operating speeds require greater torque-motor to deliver the same rotoric power of motors of higher revolutions; this is reflected in the sizing of this type of machine due to the assembly of more solid components for operability [2]. Since, these induction motors are described as a non-linear system because the speed and load condition present sudden jumps [3], so the presence of a special controller that provides vector or scalar control, is useful depending on the application area [4].

Among the different methods of electrical drive of these machines, the establishment of a variable frequency drive (VDF), based on microprocessors and power electronics components[5, 6, 7]; Of which this operation of speed control in Alternating Current (AC) motors, consequently implies the reduction of wear of electro-mechanical components, such as the rotor conductive bars, which lead to one of the probabilities of failures; and a decrease between $20 \%$ and $60 \%$ of electrical energy consumption under the same load conditions[8]. The most recurrent VDF model for this application, works under the principle of Power Weight Modulation PWM [9] and this operating mechanism lies explicitly in the reduction or increase of the duration of the series of pulses that allow the control mode depending on the adjustment of the voltage and frequency of the power supply network [10].

Given the significant reduction in energy due to the use of this device, the presence or origin of the harmonic content generated by the grid expressed in the Total Harmonic Distortion (THD) is negligible, although this concept is specified according to the operating conditions and nominal load of the electric motor [11], given that, the VDF is used in specific sectors where they require a negligible THD, it should be noted that these optimal values are exclusive for quasistable frequency values; That is, not for applications of continuous velocity variations [12].

It should be noted that this presence of the harmonic spectrum influences the emission of thermal energy, about an additional 5\%, in the engine that is operating at nominal load. On the other hand, the rectification of the power factor (f.p.) is developed based on the reduction of the phase angle between the current and voltage established by the VDF $[13,14]$.

In this sense, this article aims to determine the operational behavior of asynchronous motor controlled by frequency inverter applied in a fatigue test system for analysis of standardized specimens subjected to conditioned tensioncompression. Therefore, the purpose of this is to analyze the benefits and particularities caused by the use of controllers such as the frequency inverter.

\section{LITERATURE REVIEW}

If we assume that the excessive electronic control equipment consequently generates electrical noises, deformations and harmonics these can be evaluated to counteract them by power electronics, after analysis of the particular, but it is possible when it comes to a line of several motors, the cost is contemplated; Likewise, also ensuring [15].

Electric machines necessarily require reliable protection systems that involve additional expenses; however, among the 
advantages of VDF, in addition to speed control, are the safety functionalities where the VDF presents algorithms that guarantee an instant response before possible failure scenarios, as reaffirmed [16] in his case study. These unfavorable scenarios can be: low starting current (ramp), dynamic braking (under reverse magnetic shock), reversal of rotation, absence of phase, imbalance of phases, among others; supplying mechanisms for starting, safety and braking of the electric motor.

\section{RESEARCH METHOD}

\section{A. Data Logging Processes}

The model under study is composed of elements: mechanical, electrical, electronic, among others. Which we can show in Fig. 1, arranged according to their function, being able to be static and/or dynamic. Which we can classify into three systems: Control (command), Actuator (force) and Monitoring; All these are listed in Fig. 2 and Fig. 3 This composition consists of:

1) A three-phase network called L1, L2, L3, (220V 60Hz), where only two phases (L1 L2) are used to power the VDF.

2) A Siemens Micromaster 440 frequency inverter (attach tab as required), which was preconfigured with the plate data "Parameters"; In addition, peripherals were connected as an external control system composed of: Switch type switch (digital input), which enables the entire external control panel; Switch 1 - 0 - 2 (digital input), makes the so-called rotation inversion; Potentiometer (analog input), Performs the increase or decrease in speed as needed.

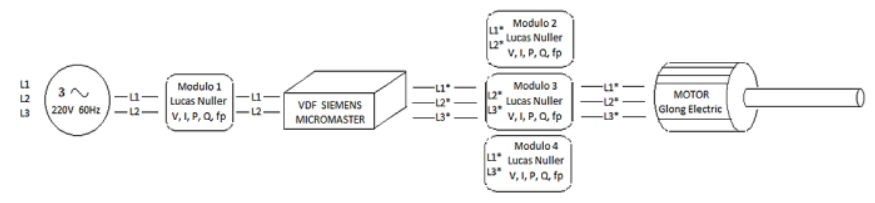

Fig. 1. A Three-phase Network VDF Connection Diagram.

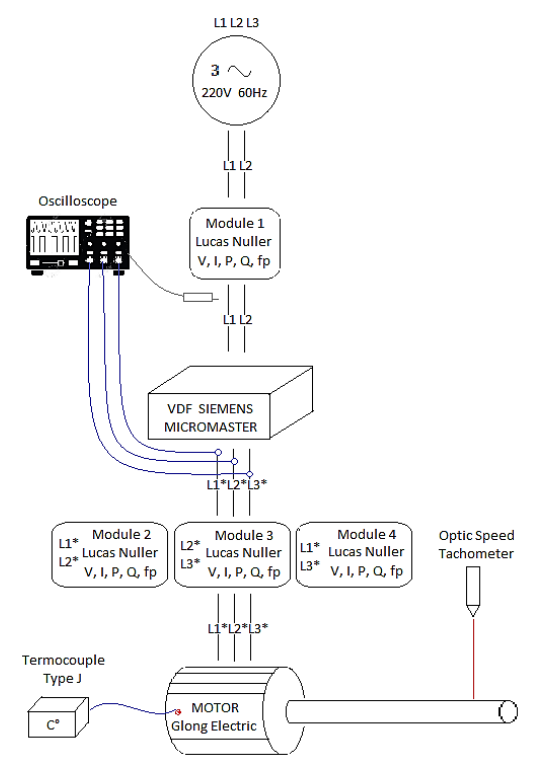

Fig. 2. A Siemens Micromaster 440 frequency inverter (VDF Connection Diagram).

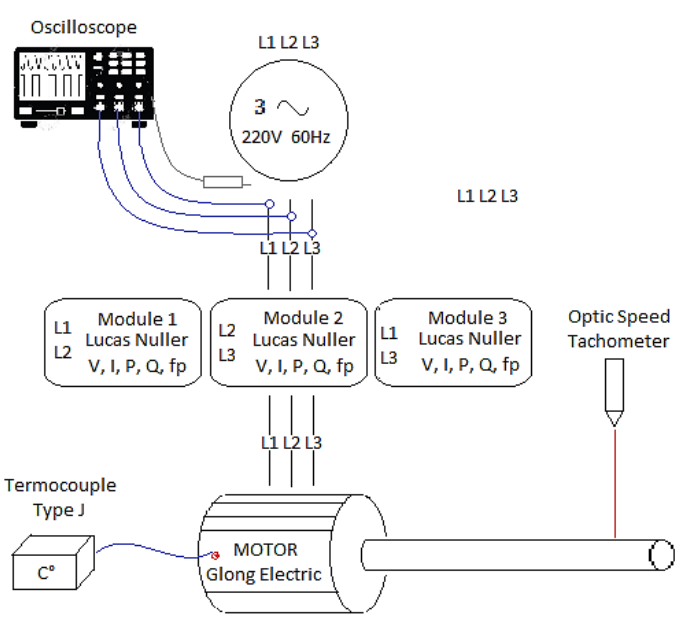

Fig. 3. Direct Boot Connection Diagram.

3) A fatigue test machine where a class A-36 specimen was analyzed during the study, see Fig 5; Which consisted of a $61.9 \%$ nominal load for the induction motor.

4) An optical light tachometer (Standard ST6236B Tachometer) (see Fig. 5).

5) A digital oscilloscope (Instek GDS-2064) which registers an admission signal to the drive (L1 L2); drive output signal $(\mathrm{L} 1 * \mathrm{~L} 2 * \mathrm{~L} 3 *)$

6) Lucas Nuller measurement modules, obtaining (V, I, P, Q, f.p), which were located as follows: Red section - VDF input; VDF - Motor section, one module for each pair of phases (L1-L2/L2-L3/L1-L3); That is, in general it consisted of four modules (see Fig. 4).

\section{B. Theoretical Bases}

A theoretical part of the subject of the study is based on the behavior of the asynchronous or induction electric motor according to its operability-configuration, which obey laws of electrostatics.

In induction motors the variation of the simultaneous speed developed by the rotating rotor and rotary magnetic field is generated, this behavior of asynchronism is called slippage [17].

The rotor velocity Equation $1\left(n_{r}\right)$ of these electrical machines is given by the following expression:

$\mathrm{n}_{\mathrm{r}}=\left[120 \times \mathrm{f} \times \frac{(1-\mathrm{s})}{\mathrm{P}}\right](\mathrm{r} / \mathrm{min})$

Where (f) is the wave frequency in units of $\mathrm{Hz}$, (s) is the slippage expressed in percentage value and $(\mathrm{P})$ is the number of magnetic poles.

The difference of this speed with respect to the speed of synchronism is represented according to Equation 2.

$\mathrm{n}_{d}=\mathrm{n}_{\mathrm{s}}-\mathrm{n}_{\mathrm{r}}(\mathrm{r} / \mathrm{min})$

Where $\left(n_{d}\right)$ is the sliding velocity and $\left(n_{s}\right)$ is considered precisely the velocity of the magnetic field of the stator.

The description of these motors is similar to a rotary transformer; According to the secondary windings constituted 
in the rotor design of the motor, they generate a power flow output mechanically due to the short-circuited system of the coupled windings [18].

This useful power is directly related to the torque induced in the machine, such torque is the result of the difference of the actual torque at the engine terminals and the torque produced by friction and friction with air in this equipment [19]; therefore, the developed mechanical power $\left(\mathrm{P}_{\mathrm{mec}}\right)$ is expressed by the following Equation 3:

$\mathrm{P}_{\mathrm{mec}}=\frac{\tau_{\text {ind }} \times \mathrm{n} \times \pi}{30}(\mathrm{~W})$

Where $\left(\tau_{\text {ind }}\right)$ is also called motor torque expressed in N-m, and $\left(\mathrm{n}_{\mathrm{r}}\right)$ the rotational speed expressed in RPM.

In asynchronous motors the slip mainly influences the performance result, since the lower the slip value an acceptable efficiency is obtained [1, 17], specifically interpreted in the rotor performance Equation $4\left(\eta_{\mathrm{r}}\right)$ :

$\eta_{\mathrm{r}}=1-\mathrm{s}=\frac{\mathrm{P}_{\mathrm{EM}}}{\mathrm{P}_{\mathrm{S}}}$

Where $\left(\mathrm{P}_{\mathrm{EM}}\right)$ is the internal mechanical power and $\left(\mathrm{P}_{\mathrm{S}}\right)$ is the interlocking power that reaches the rotor. From the power supply, the motor is supplied with electrical power which is classified as $\left(\mathrm{P}_{\text {Absorbed }}\right)$ recorded in the input conductors of the machine, in full operation mechanical power expressed as $\left(\mathrm{P}_{\text {Util }}\right)$ is released, this variable differs with the input power due to iron losses, copper and thermally dissipated mechanics.

$\eta=\frac{P_{\text {útil }}}{P_{\text {absorbed }}}=\frac{P_{\text {output }}}{P_{\text {input }}}=\frac{P_{\text {Mechanical }}}{P_{\text {Electrical }}}=\frac{H P \times 746}{\sqrt{3} \times \mathrm{V} \times \mathrm{I} \times \cos \varphi}$

It is considered that the increase in the feeding frequency influences the decrease in reactive power of magnetization. Since, the reactive energy is consumed when the asynchronous motor performs an operation in vacuum, according to the impedance of the motor, it causes a high angle of lag between voltage and current, consequently, a low $\operatorname{Cos}(\varphi)$ [20].

In the mechanism of drive of asynchronous motors, the transient stage is taken into consideration when the change of state is developed by increase or variation of speed where there are various methods of analysis, of which emphasis is taken to the frequency inverter VDF used to control the mechanical speed of rotation of the induction motor.

\section{Basic Concepts}

Our model under study is a three-phase squirrel cage type motor in the brand "Glong Electric", asynchronous classification, denomination due to the difference in speed between the magnetic field with respect to the rotational speed, also related to sliding, has an $\mathrm{F}$ classification insulation whose working ranges around $155^{\circ} \mathrm{C}$ (IEC 60085); Also, a degree of protection with respect to solids and fluids. IP 54 (IEC 60529).

In the Table I, relevant parameters of this electric machine for the present study are detailed, which are collected according to plate data and technical sheet provided by the manufacturer.
TABLE I. ENGINE TECHNICAL SPECIFICATIONS

\begin{tabular}{|l|l|}
\hline MODEL - GLONG & MS7132 \\
\hline TYPE & 1 \\
\hline HP & 220 \\
\hline (D) V & 380 \\
\hline (Y) V & 3.3 \\
\hline (D) I & 1.93 \\
\hline (Y) I & 2 \\
\hline POLES & 0.75 \\
\hline KW & 60 \\
\hline HZ & 3300 \\
\hline RPM & 0.82 \\
\hline Cos $(\varphi)$ & 1111103 \\
\hline NO. & 0.727 \\
\hline$\eta$ &
\end{tabular}

Likewise in Table II, the machine would be considered at full load if the consumption was the nominal intensity, but for our case the applied load only represents $61.9 \%$.

TABLE II. ENGINE TECHNICAL SPECIFICATIONS

\begin{tabular}{|l|l|l|}
\hline Rated Load & {$[\mathrm{A}]$} & 3.30 \\
\hline Current Load & {$[\mathrm{A}]$} & 2.04 \\
\hline Percentage Load & {$[\%]$} & 61.90 \\
\hline
\end{tabular}

\section{Overview of Experimental Analysis}

During the experimentation, the most relevant electrical parameters were analyzed and documented, which were synthesized in Excel calculation tables, which consist of two analyses, where the Tables III, IV and V correspond to the first analysis; also, for the second analysis consist of two Tables VI and VII. However, these parameters were obtained through different methodologies.

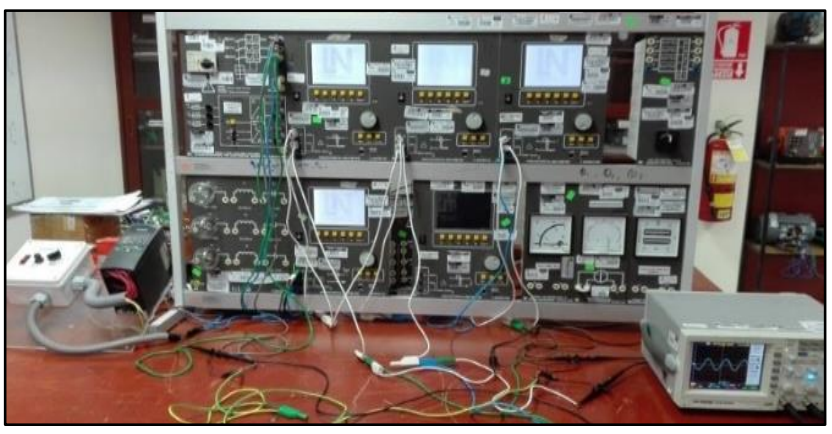

Fig. 4. Experimental Instrumentation System.

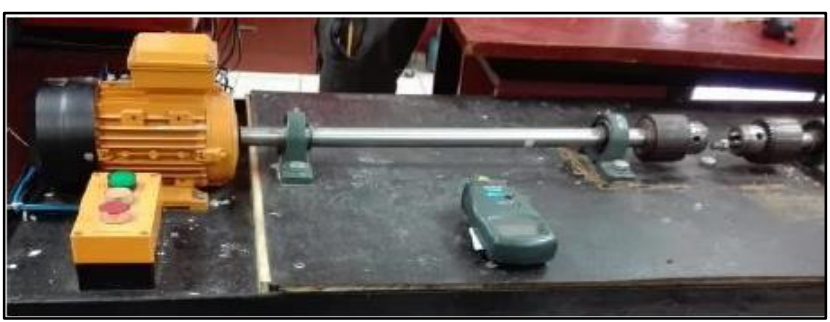

Fig. 5. Fatigue Analysis System. 
So, we have in Fig. 4: Lucas Nuller modules (V-1Ø, I, f.p $(\operatorname{Cos}(\varphi))$; Oscilloscope (amplitude, frequency); Tachometer (RPM); parameters obtained through national electrical portals COES SEIN (frequency); Parameters obtained by calculations, using the equations described in the theorical bases section. powers $3 \varnothing$ "P-Q-S", Angle $\left(\varphi^{\circ}\right)$, mechanical power (Equation 3 ), torque (Equation 3), magnetic field speed, slippage (Equation 2).

In this Fig. 5 we have a partial view of the driving part of the modular fatigue stress analysis system, where in: on the right side, rotating mechanical parts corresponding to the load of the electric machine are observed (rowlocks, specimen, dynamometer, etc.); Similarly, we have on the left side the electric machine, which is the object of study in this article.

\section{ANALYSIS}

\section{A. First Analysis}

Tables corresponding to those obtained during the operation of the asynchronous motor by means of a VDF, where Table III corresponds to the supply with two live phases; Also, Table IV corresponds to the output of three quasialternating live phases of the VDF which are directed to the terminal box of the three-phase motor.

TABLE III. ELECTRICAL PARAMETERS AT THE VDF INPUT

\begin{tabular}{|c|c|c|c|c|c|}
\hline \multicolumn{6}{|c|}{ INPUT OF THE V.D.F. 1Ø VAC - CONNECTION $(\Delta)$} \\
\hline \multicolumn{6}{|c|}{ ENGINE ELECTRIC PARAMETER - EXPERIMENTAL } \\
\hline $\mathbf{f}[\mathrm{HZ}]$ & $\mathbf{V}_{(\text {L1-L2) }}$ & $\mathbf{I}[\mathbf{A}]$ & $\mathbf{P}[\mathbf{W}]$ & $\mathbf{Q}$ & $\mathbf{S}$ \\
\hline 59.951 & 224.10 & 0.87 & 96.70 & 169.29 & 194.97 \\
\hline 60.024 & 223.40 & 0.88 & 96.90 & 170.82 & 196.59 \\
\hline 59.948 & 223.70 & 0.93 & 104.00 & 180.17 & 208.04 \\
\hline 60.013 & 223.50 & 0.91 & 101.50 & 176.49 & 203.39 \\
\hline 60.003 & 224.40 & 0.91 & 101.20 & 177.20 & 204.20 \\
\hline 59.944 & 224.20 & 0.90 & 100.70 & 175.09 & 201.78 \\
\hline 60.022 & 225.10 & 0.92 & 103.60 & 179.59 & 207.09 \\
\hline 59.98 & 225.30 & 0.97 & 109.70 & 188.88 & 218.54 \\
\hline 59.997 & 225.00 & 0.99 & 112.80 & 192.39 & 222.75 \\
\hline 60.042 & 225.20 & 1.04 & 119.40 & 201.74 & 234.21 \\
\hline 60.063 & 225.00 & 1.10 & 127.10 & 212.75 & 247.50 \\
\hline 60.021 & 225.10 & 1.16 & 133.90 & 224.29 & 261.12 \\
\hline 60.033 & 224.80 & 1.24 & 145.10 & 238.10 & 278.75 \\
\hline 60.015 & 224.50 & 1.23 & 142.50 & 236.20 & 276.14 \\
\hline 60.008 & 224.10 & 1.31 & 153.90 & 250.22 & 293.57 \\
\hline 60.007 & 223.80 & 1.40 & 164.70 & 266.47 & 313.32 \\
\hline 59.999 & 223.90 & 1.44 & 170.70 & 273.61 & 322.42 \\
\hline 59.967 & 223.50 & 1.51 & 179.60 & 285.55 & 337.49 \\
\hline 60.053 & 223.40 & 1.56 & 185.70 & 294.43 & 348.50 \\
\hline 60.061 & 223.50 & 1.58 & 196.30 & 298.12 & 353.13 \\
\hline 60.025 & 223.40 & 1.77 & 215.40 & 331.79 & 395.42 \\
\hline 59.991 & 223.40 & 1.80 & 218.10 & 337.67 & 402.12 \\
\hline 60.022 & 223.20 & 1.88 & 230.70 & 351.00 & 419.62 \\
\hline 60.103 & 223.00 & 2.06 & 254.30 & 382.75 & 459.38 \\
\hline
\end{tabular}

TABLE IV. ElECtRicAl PARAMETERS RECORDED AT THE OUTPUT OF THE VDF

\begin{tabular}{|c|c|c|c|c|c|c|}
\hline \multicolumn{7}{|c|}{ OUTPUT OF THE V.D.F. 3Ø VAC' - CONNECTION $(\Delta)$} \\
\hline \multicolumn{7}{|c|}{ ENGINE ELECTRIC PARAMETER - EXPERIMENTAL } \\
\hline $\mathbf{f}[\mathbf{H Z}]$ & $\mathbf{n}_{\mathbf{r}}[\mathbf{R P M}]$ & $\mathbf{V}_{\text {Fase' }}(*)$ & $\mathbf{I}_{\text {Fase }}$ & $\mathbf{P}[\mathbf{W}]$ & $\mathbf{Q}$ & $\mathbf{S}$ \\
\hline 2.26 & 143.20 & 15.05 & 2.60 & 67.37 & 7.41 & 67.78 \\
\hline 5.06 & 243.40 & 14.20 & 2.67 & -59.43 & 27.94 & 65.67 \\
\hline 7.53 & 438.80 & 20.24 & 2.75 & -87.34 & 40.81 & 96.41 \\
\hline 10.10 & 590.90 & 34.70 & 2.49 & -127.80 & 77.86 & 149.65 \\
\hline 12.58 & 737.60 & 42.50 & 2.30 & -132.23 & 105.74 & 169.31 \\
\hline 15.08 & 886.20 & 51.70 & 2.16 & 148.55 & 123.88 & 193.42 \\
\hline 17.29 & 1017.00 & 59.20 & 2.05 & 158.49 & 138.08 & 210.20 \\
\hline 20.00 & 1180.00 & 67.40 & 2.05 & 179.97 & 157.75 & 239.32 \\
\hline 22.54 & 1331.00 & 76.50 & 1.99 & 190.64 & 182.16 & 263.68 \\
\hline 25.10 & 1484.00 & 85.60 & 1.96 & 210.97 & 199.84 & 290.60 \\
\hline 27.51 & 1628.00 & 94.40 & 1.95 & 232.75 & 217.91 & 318.84 \\
\hline 30.21 & 1788.00 & 103.40 & 1.90 & 248.74 & 232.20 & 340.28 \\
\hline 32.58 & 1929.00 & 112.60 & 1.93 & 270.26 & 261.99 & 376.41 \\
\hline 35.19 & 2084.00 & 113.50 & 1.93 & 281.90 & 253.94 & 379.41 \\
\hline 37.69 & 2232.00 & 121.30 & 1.93 & 297.63 & 275.39 & 405.49 \\
\hline 40.26 & 2383.00 & 131.00 & 1.92 & 318.02 & 297.74 & 435.65 \\
\hline 42.45 & 2518.00 & 138.80 & 1.82 & 321.16 & 297.16 & 437.54 \\
\hline 45.32 & 2690.00 & 147.60 & 1.92 & 358.81 & 334.94 & 490.85 \\
\hline 47.50 & 2821.00 & 156.30 & 1.90 & 376.52 & 350.44 & 514.37 \\
\hline 50.50 & 3000.00 & 165.70 & 1.92 & 403.91 & 374.83 & 551.04 \\
\hline 52.55 & 3122.00 & 183.20 & 1.86 & 446.19 & 386.33 & 590.20 \\
\hline 55.10 & 3275.00 & 193.70 & 1.89 & 469.86 & 425.80 & 634.09 \\
\hline 57.54 & 3420.00 & 202.60 & 1.89 & 495.43 & 440.93 & 663.23 \\
\hline 59.88 & 3557.00 & 218.70 & 1.88 & 546.21 & 456.94 & 712.14 \\
\hline
\end{tabular}

The Table V, presents six variables under analysis, where the only one obtained experimentally is the $\operatorname{Cos}(\varphi)$; Otherwise with the other variables which are a consequence of the calculations made, based on theoretical bases described above.

Once the values obtained by instrumentation (Table III, Table IV) and calculations in Table V have been admitted and synthesized, we proceed to make graphical representations of the most relevant electrical parameters, including those that are the object of analysis.

In all cases the representations correspond to figures obtained by Module 1 and Module (2, 3 and 4) nomenclature specified in Fig. 1, Fig. 2 and Fig. 3. Parameters represented by IBM SPSS interfaces, corresponding to V, I, P, Q, S and f.p. 
TABLE V. CALCULATED ELECTRICAL PARAMETERS OF THE VDF OUTPUT

\begin{tabular}{|c|c|c|c|c|c|}
\hline OUTP & DF THE V. & X VAC' - C & NECTIC & $(\Delta)$ & \\
\hline ENGII & LECTRIC & METER - & LCULA & & \\
\hline $\operatorname{Cos}(\varphi)$ & $\mathbf{P}_{\text {rotor }}[\mathbf{W}]$ & $M[N-m]$ & $\mathbf{n}_{\mathrm{s}}$ & $\mathbf{n}_{\mathrm{d}}$ & PAR Axis \\
\hline 0.064 & 2.748 & 0.183 & 135.6 & -7.6 & 6.13 \\
\hline-0.897 & -38.140 & -1.496 & 303.6 & 60.2 & 2.66 \\
\hline-0.877 & -62.479 & -1.360 & 451.8 & 13.0 & 2.93 \\
\hline-0.029 & -2.845 & -0.046 & 606.0 & 15.1 & 3.25 \\
\hline-0.768 & -88.163 & -1.141 & 754.8 & 17.2 & 3.26 \\
\hline 0.752 & 96.376 & 1.039 & 904.8 & 18.6 & 3.25 \\
\hline 0.745 & 104.240 & 0.979 & 1037.4 & 20.4 & 3.26 \\
\hline 0.736 & 116.345 & 0.942 & 1200.0 & 20.0 & 3.20 \\
\hline 0.716 & 125.036 & 0.897 & 1352.4 & 21.4 & 3.23 \\
\hline 0.716 & 138.424 & 0.891 & 1506.0 & 22.0 & 3.25 \\
\hline 0.718 & 151.480 & 0.889 & 1650.6 & 22.6 & 3.27 \\
\hline 0.723 & 163.605 & 0.874 & 1812.6 & 24.6 & 3.25 \\
\hline 0.715 & 178.154 & 0.882 & 1954.8 & 25.8 & 3.29 \\
\hline 0.726 & 181.360 & 0.831 & 2111.4 & 27.4 & 3.06 \\
\hline 0.726 & 192.424 & 0.823 & 2261.4 & 29.4 & 3.05 \\
\hline 0.730 & 208.379 & 0.835 & 2415.6 & 32.6 & 3.09 \\
\hline 0.727 & 213.574 & 0.810 & 2547.0 & 29.0 & 3.11 \\
\hline 0.725 & 233.116 & 0.828 & 2719.2 & 29.2 & 3.10 \\
\hline 0.727 & 243.788 & 0.825 & 2850.0 & 29.0 & 3.12 \\
\hline 0.728 & 261.079 & 0.831 & 3030.0 & 30.0 & 3.12 \\
\hline 0.739 & 285.699 & 0.874 & 3153.0 & 31.0 & 3.31 \\
\hline 0.734 & 303.833 & 0.886 & 3306.0 & 31.0 & 3.33 \\
\hline 0.737 & 319.061 & 0.891 & 3452.4 & 32.4 & 3.34 \\
\hline 0.754 & 351.097 & 0.943 & 3592.8 & 35.8 & 3.47 \\
\hline
\end{tabular}

For Fig. 6, the intake voltage at all analysis points is within the maximum permissible ranges of $+/-5 \%$. However, at the output of the VDF in all cases it presents a stable increase, corresponding to the directly proportional increase of the frequency in selected analysis.

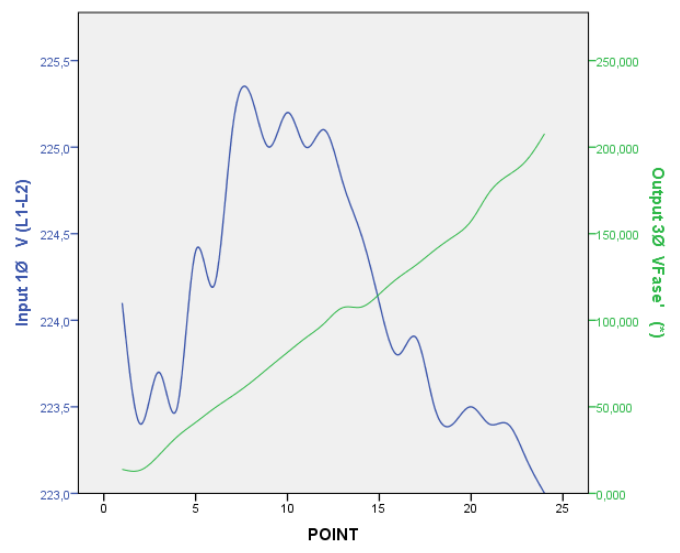

Fig. 6. Analysis of $1 \varnothing(\mathrm{V})$ and $3 \varnothing(\mathrm{V})$.

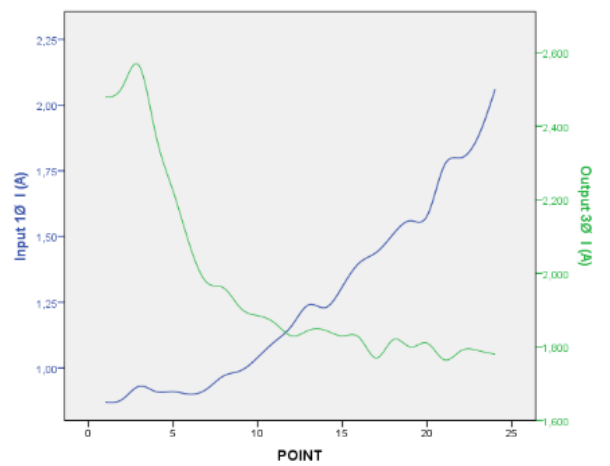

Fig. 7. Analysis of $1 \varnothing(\mathrm{A})$ and $3 \varnothing(\mathrm{A})$.

The output intensity of the VDF presents an increase in peak value, due to the low starting frequency, in addition to the natural inertial load of the rotor and including the load; however, this peak is temporary, since it presents a beneficial decrease in time, in inverse relation to the frequency. However, in the admission of the VDF presents a quasi-constant proportional increase.

Likewise; Regarding the Fig. 7, we can affirm that the use of VDF is profitable at low frequencies, since the consumption of the network is lower than the output of the VDF. Where the point of non-profitability would be around 12 where the frequency is around $30.21 \mathrm{HZ}$.

Given this representation Fig. 8, we can reaffirm one of the greatest virtues of the VDF, which consists in the reduction of energy consumption of the electricity grid. Where according to the graph at all times the active power of the network is lower, than that of the output of the VDF.

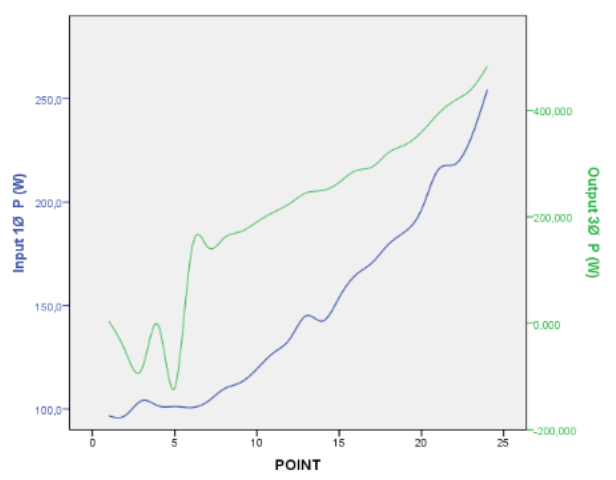

Fig. 8. Analysis of $1 \varnothing(\mathrm{W})$ and $3 \varnothing(\mathrm{W})$.

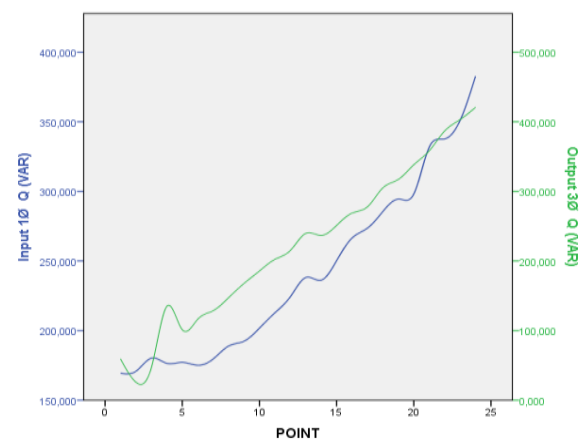

Fig. 9. Analysis of $1 \varnothing$ (VAR) and $3 \varnothing$ (VAR). 
Given the interpretation of the graph (Fig. 9), we can affirm that the reactive power in the output of the VDF is greater than that of the network for all the frequencies analyzed, which has similitude to a circuit with a reactive energy compensation system.

Apparent powers are also considered one of the most important parameters of a power triangle. This is a consequence of vector considerations of the f.p, active and reactive powers that is why we can affirm through its graph (Fig. 10), that the use of a VDF reduces energy consumption, without affecting the electrical or mechanical power of the induction motor.

Having simulated several representative waves of ideal waves using software PSIM, we make available the waveforms obtained by the function generator, which we show in Fig. 11. Being able to show the distortions caused in the fundamental wave by the use of a VDF.

Similarly in Fig 12, the waveforms generated by a frequency inverter; That is, the one we make available to the cargo.

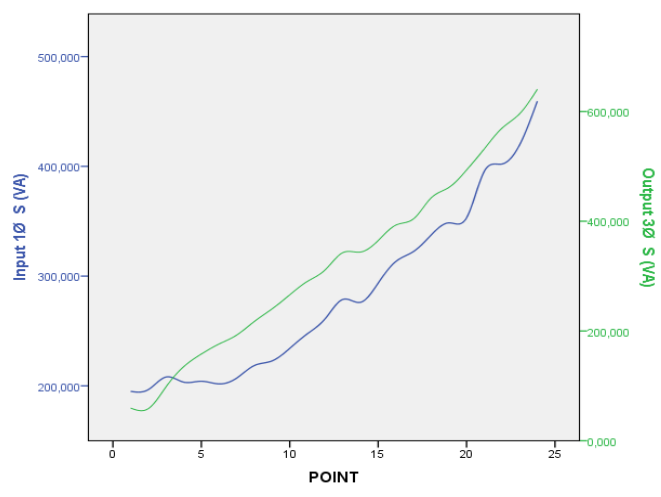

Fig. 10. Analysis of $1 \varnothing(\mathrm{VA})$ and $3 \varnothing(\mathrm{VA})$.

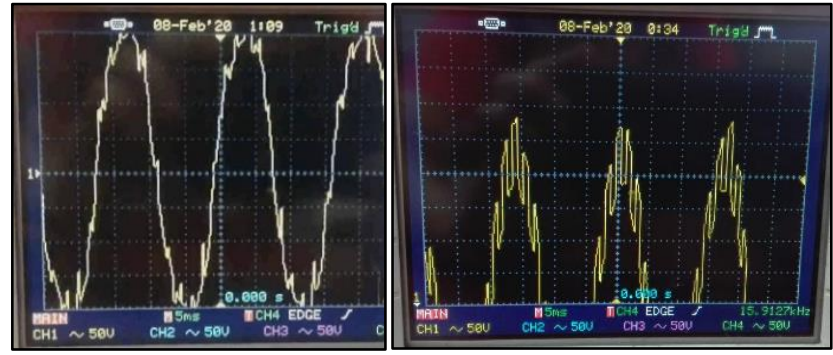

Fig. 11. Harmonic Distortion Caused by the use of a Variable Frequency Drive.
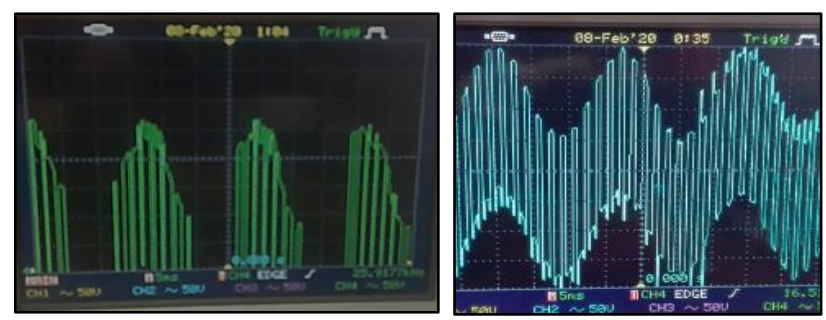

Fig. 12. Quasi-Sine Waveform Generated by the Variable Frequency Drive to make the Load Available.

\section{B. Second Analysis}

From now on we start a new analysis; where we compare the rotary machine, operating on a regular basis with a direct starting system using contactors Fig. 3 and a second using a VDF with ramp starting system Fig. 2; but, both with delta connection. The electrical parameters obtained were arranged in tables, respectively (Table VI and Table VII).

TABLE VI. Electrical Parameters IN Single-Phase AND THREePHASE REGISTERED WITHOUT VDF

\begin{tabular}{|c|c|c|c|c|}
\hline \multicolumn{5}{|c|}{ WITHOUT V.D.F. VAC } \\
\hline \multicolumn{5}{|c|}{ ENGINE ELECTRIC PARAMETER } \\
\hline \multirow{3}{*}{ CONNEC. } & \multicolumn{4}{|c|}{ TRIANGLE ${ }^{(* *)}$} \\
\hline & \multicolumn{3}{|l|}{$1 \varnothing$} & \multirow[t]{2}{*}{$3 \varnothing$} \\
\hline & LINE 1 & LINE 2 & LINE 3 & \\
\hline $\mathbf{f}[\mathbf{H Z}]$ & 59.94 & 59.94 & 59.94 & 59.94 \\
\hline$n_{r}[R P M]$ & 3560.00 & 3560.00 & 3560.00 & 3560 \\
\hline $\mathbf{V}_{\text {(L1-L2) }}[\mathbf{V}]$ & 224.80 & 225.20 & 224.00 & 224.67 \\
\hline $\mathbf{I}[\mathbf{A}]$ & 1.99 & 2.04 & 2.10 & 2.04 \\
\hline $\mathbf{P}[\mathbf{W}]$ & 360.00 & 364.80 & 370.00 & 364.93 \\
\hline Q [VAR] & 280.00 & 288.50 & 300.00 & 289.50 \\
\hline $\mathbf{S}[\mathbf{V A}]$ & 447.00 & 456.90 & 470.00 & 457.97 \\
\hline $\operatorname{Cos}(\varphi)$ & 0.79 & 0.77 & 0.78 & 0.78 \\
\hline$\varphi^{\circ}$ & 37.44 & 39.24 & 38.92 & 38.54 \\
\hline $\operatorname{Sen}(\varphi)$ & 0.61 & 0.63 & 0.63 & 0.62 \\
\hline $\mathbf{P}_{\text {Mechanics }}[\mathbf{W}]$ & 261.72 & 265.21 & 268.99 & 265.307 \\
\hline$M[\mathbf{N}-\mathbf{m}]$ & 0.70 & 0.71 & 0.72 & 0.712 \\
\hline $\mathbf{n}_{\mathrm{s}}$ & 3596.64 & 3596.64 & 3596.64 & 3596.64 \\
\hline $\mathbf{n}_{\mathrm{d}}$ & 36.64 & 36.64 & 36.64 & 36.64 \\
\hline PAR $_{\text {Axis }}$ & 3.75 & 3.76 & 3.74 & 3.75 \\
\hline
\end{tabular}

In the Table VII, we make the comparison under similar operating conditions with the exception of considering in the installation a VDF "C/VDF" (see Fig. 2) or not using it "S / VDF" (see Fig. 3).

From now on we proceed to perform the validation of the results obtained by Power Simulation Software (PSIM), for this we start by making the representative equivalent diagrams in the software interfaces, where we also declare the nomenclatures and denominations of the instruments, to analyze subsequent representations that preserve the same nomenclatures.

We can deduce the following diagram as the electrical interpretation of Fig. 2. Where modules (2, 3 and 4) are presented as a composition of instruments specific to each parameter. In addition to performing the electrical representation of a rotating electric machine by its equivalent impedance (resistance " $r$ " and inductive reactance "xl") Of similar characteristics to the previous wing, the present representation corresponds to the electrical interpretation of Fig. 3 with similar contemplations with respect to instruments and equivalent electrical circuits described in Fig. 13. 
TABLE VII. COMPARATIVE ANALYSIS OF THE C/S VDF TESTS

\begin{tabular}{|c|c|c|}
\hline \multirow{3}{*}{ CONNEC. } & C/ VDF & S/VDF \\
\hline & \multicolumn{2}{|c|}{ TRIANGLE } \\
\hline & $3 \emptyset \mathrm{VAC}^{\prime}$ & $3 \emptyset \mathrm{VAC}$ \\
\hline f [HZ] & 59.88 & 59.94 \\
\hline$n_{r}[R P M]$ & 3557.00 & 3560.00 \\
\hline $\mathbf{V}_{(\mathbf{L 1}-\mathrm{L} 2)}[\mathbf{V}]$ & 207.75 & 224.67 \\
\hline $\mathbf{I}[\mathbf{A}]$ & 1.78 & 2.04 \\
\hline $\mathbf{P}[\mathbf{W}]$ & 482.94 & 420.73 \\
\hline Q [VAR]. & 420.73 & 289.50 \\
\hline $\mathbf{S}$ [VA] & 640.50 & 457.97 \\
\hline $\operatorname{Cos}(\varphi)$ & 0.75 & 0.78 \\
\hline$\varphi^{\circ}$ & 41.06 & 38.54 \\
\hline $\operatorname{Sen}(\varphi)$ & 0.66 & 0.62 \\
\hline $\mathbf{P}_{\text {Mechanics }}[\mathbf{W}]$ & 351.10 & 265.31 \\
\hline$M[N-m]$ & 0.94 & 0.71 \\
\hline $\mathbf{n}_{\mathrm{s}}$ & 3592.80 & 3596.64 \\
\hline $\mathbf{n}_{\mathrm{d}}$ & 35.80 & 36.64 \\
\hline PAR $_{\text {Axis }}$ & 3.47 & 3.75 \\
\hline
\end{tabular}

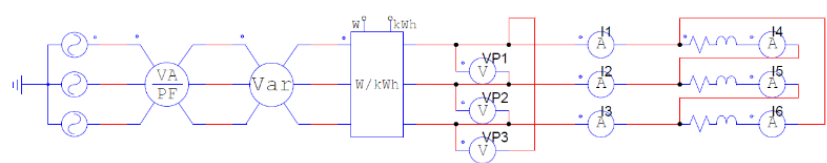

Fig. 13. Electrical Parameter Measurement Diagram with VDF.

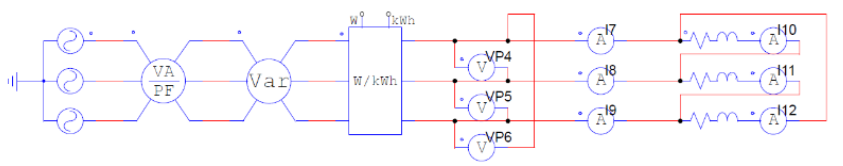

Fig. 14. Electrical Parameter Measurement Diagram without VDF.

The Fig. 15 correspond to those obtained by instruments called voltmeters with the nomenclature VP1, VP2, VP6 (Fig. 13 and Fig 14), with respect to effective values. However, the exposure of the sine curves responds to those of an oscilloscope, evaluating in the first harmonic or fundamental wave.

In the Fig. 16, are represented the electrical intensities collected by ammeter for effective values. Also, for those corresponding to that of an oscilloscope, where they provide maximum, minimum values and other characteristics of this generator. In all cases they represent the line intensities in both analyses.

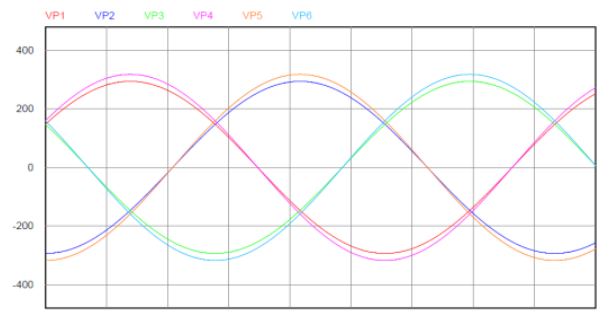

Fig. 15. Line Voltage Curves c/s VDF.

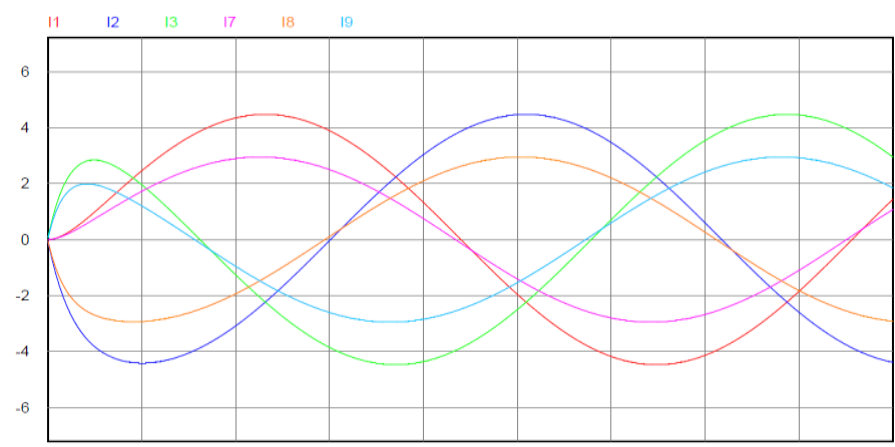

Fig. 16. Curves of the Line Current c/s VDF.

The following graph called Fig. 17 corresponds to those obtained from similar conditions to the previous figures, with the exception that these represent the electrical intensities of phase. If we remember in a typical connection of an electric machine of 6 terminals, connected in delta (triangle), the line intensities are root of three times phase wings.

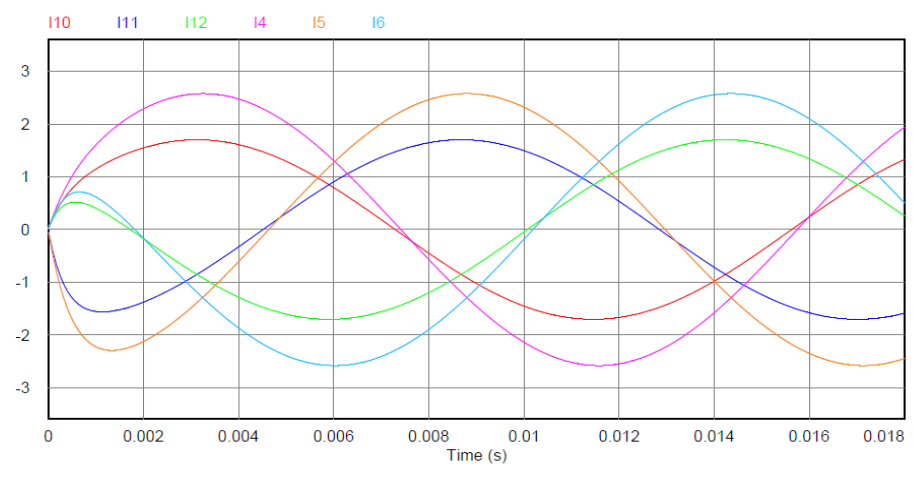

Fig. 17. Curves of the Phase Current c/s VDF.

This Fig. 18 corresponds to the effective values and maximum values of voltage and current. Obtained by the instrumentation modules and equivalent measuring instruments in Fig. 13 and Fig 14. In addition, these values can be contrasted with those obtained experimentally in Table VII.

RMS Value

Time From $1.0000000 \mathrm{e}-00 \mathrm{~s}$

Time To $1.7940000 \mathrm{e}-002$

\begin{tabular}{l|ll|l}
\hline VP1 & $2.0746762 e+002$ & 17 & $2.0149252 e+000$ \\
VP2 & $2.1393670 e+002$ & 18 & $2.0910262 e+000$ \\
VP3 & $2.0166419 e+002$ & 19 & $2.0594404 e+000$ \\
VP4 & $2.2436163 e+002$ I10 & $1.1843110 e+000$ \\
VP5 & $2.3135749 e+002$ I11 & $1.2095659 e+000$ \\
VP6 & $2.1808563 e+002112$ & $1.1657161 e+000$ \\
I1 & $3.0526435 e+000^{14}$ & $1.7870206 e+000$ \\
I2 & $3.1420231 e+00015$ & $1.8168283 e+000$ \\
13 & $3.1049799 e+000^{16}$ & $1.7653063 e+000$
\end{tabular}

Fig. 18. Effective Parameters c/s VDF. 


\section{Temperature $\left[{ }^{\circ} \mathrm{C}\right]$ VS Frecuency $[\mathrm{Hz}]$}

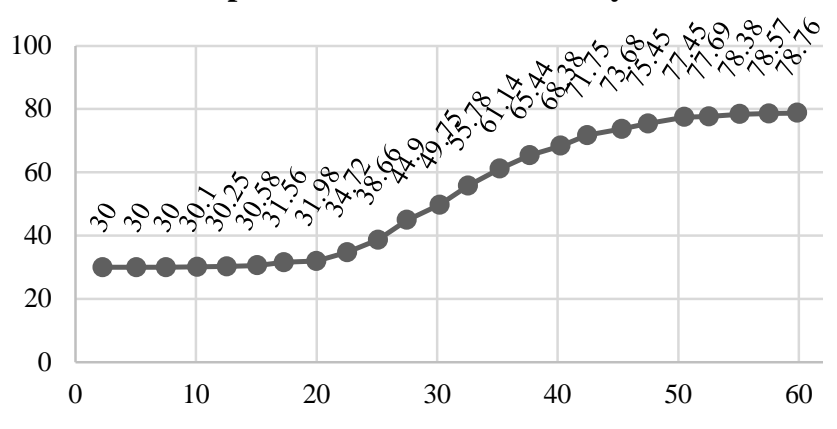

Fig. 19. Temperature Values of the Induction Motor with VDF.

One of the parameters considered of high importance in the useful life of electrical machines is the working temperature, since this is responsible for the physical state of the insulation (windings, rotoric core, statoric core, etc.). This parameter has an impact on efficiency. Which relates the power that is absorbed from the electrical network, materializing it in losses per joule effect and minimizing the useful power; also, with respect to this we can deduce given Equation 5.

That said, in this table data collected during experimentation were synthesized, where they are in units of S.I. $\left[{ }^{\circ} \mathrm{C}\right]$, these were collected by ammeter Prasek (PR-103), in the temperature function with connection of external receiver peripheral called thermocouple type J, where the thermocouple was fixed to motor housing (see Fig. 2 and Fig. 3)

\section{DISCUSSION}

If we consider between the option of controlling the speed of a rotating machine and we opt for only 2 possibilities such as changing the number of poles or installing a vdf according to a Cost-benefit analysis, the second option would be the most convenient for the benefits of varying any RPM value with only the variation of frequencies, in addition to having protection algorithms. Likewise, it states in [7], in addition to other options that are not the subject of study.

There are control systems based on fuzzy logic in which they focus directly on the torque of the engine in the condition of operation or of certain regimes [21]; however, these would only be applicable to machines of regular work regime, the exception being those of intermittent work or irregular periods. Since these would necessarily have the phenomenon of vibrations of high torque and of different magnitudes in this regard, in [22], they point out that the claims were even higher, but for regular work regimes.

The asynchronous rotary machines have a self-coupled cooling system by constitution and composition, where the first refers to the fins of the housing, whose function is to dissipate the temperature by conduction, the temperature increases produced by the core and winding of the stator; Also, the second refers to the fan coupled to the rotary axis which directs the flow of cold air to the fins by means of the principle of forced convection; However, this fan is conditioned to the rotational speed of the rotor, where the nominal speed guarantees its efficiency; Also in [23] it is sated in regard. In the case of speed variations, they strongly impair the efficiency of this. Therefore, according to the machine dimensions, power, environmental factors, programmed rotational speeds, external ventilation systems must be chosen, guaranteeing the working temperature. Avoiding exceeding these recommended values even of " $F$ " insulation which guarantees us a maximum optimal work at the temperature of $155^{\circ} \mathrm{C}$ (IEC 60085); in this regard in [24] they also assure the same.

\section{CONCLUSION}

Electric machines have as a fundamental purpose to transform electrical energy into mechanics. So, in this article, two analyses were performed: The first, using a VDF, the torque was evaluated at different speeds (Table V); the second, making a functional comparison of the engine with and without VDF (Table VII), in both situations, only operating at nominal speeds. consequently, we can assert that, in the first case, under any frequency value assigned in the VDF the mechanical torque of the electrical machine is preserved almost constant, oscillating between $0.88(\mathrm{~N}-\mathrm{m})$; However, in the second case the electric machine has a higher torque when using the VDF; that is, with VDF $0.94 \mathrm{~N}-\mathrm{m}$ and without VDF $0.71 \mathrm{~N}-\mathrm{m}$.

Rotary electric machines have standardized operating temperatures, which meet criteria of rotational speed, mechanical load, type of bearings, insulation class, among others; Given the importance of this parameter, in our experimentation with VDF, it was determined that the working temperature increased drastically in shorter operating time, and with possibilities of increase, establishing itself at $78.76{ }^{\circ} \mathrm{C}$ (see Fig. 19); However, when the use of VDF is ignored, the engine is set to a temperature of $40{ }^{\circ} \mathrm{C}$, during any operating time. For both cases: First, the evaluation period was similar, corresponding to approximately 30 minutes, until stability was evident; Second, the percentage of mechanical load is less than the nominal, see Table II.

The power factor is directly related to the powers $(\mathrm{P}, \mathrm{Q}, \mathrm{S})$, arranged in a triangle, in relation to their nominal parameters. lower load corresponds to lower f.p. consequently greater unnecessary energy consumption, making possible alternatives such as reactive energy compensation. however, among the advantages of a VDF drive is to preserve a $\operatorname{Cos}(\varphi)$ as high as possible, but at the cost of injecting harmonics into the network. Likewise, we can see the manifestation of this event in Table VII in the electrical current apparatuses (I[Ampere]).obtaining a $\operatorname{Cos}(\varphi)$ of 0.754 despite reducing energy consumption, against a $\operatorname{Cos}(\varphi)$ of 0.782 with higher consumption. Both in equal operating conditions at $61.9 \%$ load. This value is optimal if we consider that such a machine is not operating at nominals.

The slippage is increased directly proportional to the rotational and statoric velocities (magnetic field); Then, according to the analysis carried out in Tables IV and V. We can affirm that this increase is very small, but it is preserved over time; that is, the use of a VDF does not alter its main characteristic of this type of electrical machines asynchronism. However, this slide has an average of approximately $30 \mathrm{rpm}$.

Given the analysis to Fig. 7 we can affirm, that despite the configuration of acceleration ramp, the electrical intensity presents a visible peak, because the engine starts its march in 
zero frequency; In addition to including the inertia of the natural rotoric axis with load included; However, this peak will be settling as the speed increases; Likewise, the machine has optimal energy efficiency at low frequencies, where the breaking point is approximately 12 and the corresponding frequency is around $30.21 \mathrm{HZ}$. This energy reduction can be evidenced as the curve of the intensity admitted in the VDF is lower, regarding the one supplied to the engine.

The injection of harmonics into the network is directly related to the operating frequencies of the rotating machine Fig. 12 , even more so at low frequencies, the manifestation of this phenomenon is reflected in the waveform obtained by the function generator; so, we have in Fig. 11, which shows the distortion caused in the fundamental wave.

According to the analysis in Table VI we can deduce that the dependence on reactive energy is much higher when you choose to use a VDF; however, this variable is relatively debatable, only for specific sectors where energy regulations consider in addition to active energy, reactive energy. Current regulations that contemplate tariffs and penalties, regarding consumption or injection into the interconnected electricity grid depending on whether the sector is used, distributed or transmitted.

\section{REFERENCES}

[1] M. A. Pozueta "Speed variation in asynchronous motors". University de Cantabria-Department of Electrical and Energy Engineering, Spain, 2017.

[2] H. G. ENRÍQUEZ, "Control of electric motors". Editorial Limusa. 2015.

[3] M.A. Hannan, "Optimization techniques to enhance the performance of induction motor drives." Renewable and Sustainable Energy Reviews, vol.2, no.3, pp.56-72, 2017.

[4] W. L. Bermeo, A. B de Souza, T. R. Fernandes, D. A. Honorio, L. L Nogueira-dos Reis, and L. H. Barreto "Slider mode control applied on the current mesh for an application of a base-DSP for position control of a squirrel cage induction motor". Colombian Journal of Advanced Technologies, vol. 1 no. 27, pp. 26-32, 2016.

[5] R. Bharti, M. Kumar and B. M. Prasad, "V/F Control of Three Phase Induction Motor," International Conference on Vision Towards Emerging Trends in Communication and Networking, vol. 5 no. 12, pp. Vellore, India, pp. 31-44, 2019.

[6] J. Girisha and J. Pinto, "Fuzzy Logic Controller for Indirect Vector Control of Induction Motor," Advances in Communication, Signal Processing, VLSI, and Embedded Systems, vol. 614, pp. 519-534, 2019.

[7] R. Amanz, J. Garcia and L. Miguel "Induction Motor Control Techniques: Synthesis of Current Situation." Ibero-american magazine automatic informatic industrial, vol. 13, no.2, pp.381-392, 2016.
[8] M. Ballesteros, F. Cadena and A. Jaramillo. "Signal processing techniques used for the analysis of harmonic distortion generated by variable frequency drives in induction motors." Networks of Engineering, vol. 6, no. 1, pp. 72-84, 2015.

[9] J. A. A. Gallardo, J. L. D. Rodríguez, and A. Guerrero, "Simulated annealing optimization of a single-phase multilevel converter with multi-carrier sinusoidal PWM", modulation. Colombian Journal of Advanced Technologies, vol. 1, no. 27, pp. 91-97, 2016.

[10] O. P. Ardila, "Spatial vector modulation for three-phase inverters with four switch branches". Colombian Journal of Advanced Technologies, vol. 2, no. 26, pp. 99-107, 2015.

[11] J. V. ,Gragger, A. Haumer, C. Kral and F. Pirker "Efficient Analysis of Harmonic Losses in PWM Voltage Source Induction Machine Drives with Modelica". Proceedings of the 6th Modelica Conference 2018, Bielefeld, Germany. 2018

[12] R.. Taleb, D. Benyoucef, M. Helaimi, Z. Boudjemaa, and H. saidi. "Cascaded H-bridge asymmetrical seven-level inverter using THIPWM for high power induction motor". Energy Procedia Journal, vol. 74, no. 4, pp. 844-853. 2015.

[13] G. Wang and L. Song. "Performance assessment of variable frequency drives in heating, ventilation and air-conditioning systems", Science and Technology for the Built Environment Journal, vol. 12, no. 4, pp. 456-472, 2018.

[14] Z. B. Duranay, H. Guldemir. "Selective harmonic eliminated V/f speed control of single-phase induction motor," IET Power Electronics, vol. 11, no. 3, pp. 477-483, 2017.

[15] Z. B. Duranay, H. Guldemir, "Fuzzy logic based harmonic elimination in single phase inverters". 2017 IEEE XXVI Int. Scientific Conf. “electronicsET2017”, Sozopol, Bulgaria, September 2017.

[16] D. Panasetsky, A. Osak, D. Sidorov, L. Yong. "Simplified Variable Frequency Inducton - Motor Drive Model for Power System Stability Studies and Control.” Elsevier. IFAC- Papers Online. Vol. 49, no. 27 pp. 451-454, 2016.

[17] A. Hughes. "Electric Motors and Drives". Newnes ButterworthHeinemann. 3da. ed. 185-186, 2006.

[18] S. Chapman. "Electrical Machines", 5ta ed. Mc Graw Hill.1. pp. 415416. 2012.

[19] K. S. Hoon, "Electric motor control", 1st ed. Elsevier Science, 2017.

[20] F. Petruzella. "Electric Motors and Control Systems", 2nd Edition, McGraw-Hill, 2016.

[21] O. Chamorro, N. Huaita, L. Vicuña, R, Ilizarbe, J. Torres, J. Rupay. "Experimental Analysis in Alternate Current and Direct Current of the Operating Parameters of a Universal Single-Phase Engine." Advances in Science, Technology and Engineering Systems Journal. vol. 4, no. 6, pp. 360-370, 2019.

[22] Z. Mekrini, B. Seddik. "Fuzzy Logic Application for Intelligent Control of an Asynchronous Machine," Indonesian Journal of Electrical Engineering and Computer Science, vol. 7, no. 1, pp. 61-70, 2017.

[23] E. Gundabattini, R. Kuppan, D Gnanaraj, A. Kalam, D. Kothari, R. Abu. "A Review on Methods of Finding Losses and Cooling Methods to Increase Efficiency of Electric Machines.", Ain Shams Engineering Journal. vol. 12 no. 1, pp 497-505, 2021.

[24] T. Sato, M. Enokizono. "Evaluation Of Stator Core Loss of High-Speed Motor by Using Thermography Camera.", American Institute of Physics, vol. 8, no. 4, 2017. 